
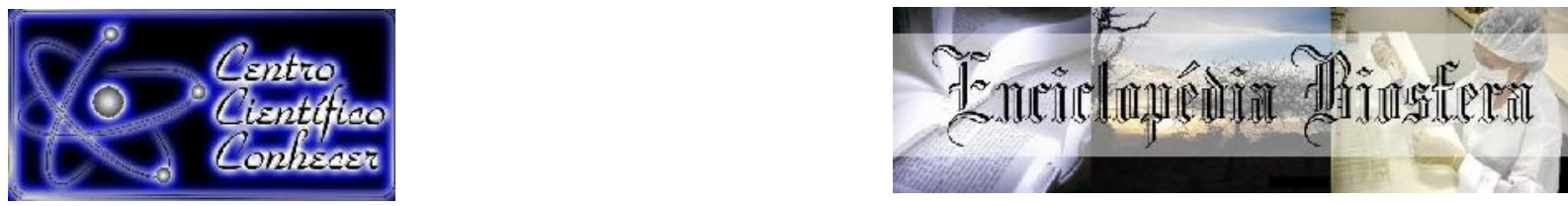

\title{
MORFOLOGIA DE Costus spiralis (JACQ.) ROSCOE (COSTACEAE): UMA ESPÉCIE MEDICINAL EM ALTA FLORESTA, MATO GROSSO
}

José Martins Fernandes ${ }^{1}$

${ }^{1}$ Universidade do Estado de Mato Grosso Carlos Alberto Reyes Maldonado (UNEMAT), Faculdade de Ciências Biológicas e Agrárias, Curso de Licenciatura e Bacharelado em Ciências Biológicas, Herbário da Amazônia Meridional, Alta Floresta, MT.

E-mail: jose.martins@unemat.br

Recebido em: 15/08/2021 - Aprovado em: 15/09/2021 - Publicado em: 30/09/2021

DOI: $10.18677 /$ EnciBio_2021C31

trabalho licenciado sob licenca Creative Commons Attribution-NonCommercial-NoDerivatives 4.0 International License.

\section{RESUMO}

O objetivo da pesquisa foi apresentar a morfologia dos órgãos vegetativos e reprodutivos de Costus spiralis (Jacq.) Roscoe no município de Alta Floresta, Mato Grosso, além de fotografias para auxiliarem na identificação da espécie, informações fitogeográficas e o seu emprego na medicina popular. Foi realizada entre abril de 2020 e agosto de 2021, mediante coleta botânica na comunidade São Bento, zona rural do município de Alta Floresta (MT). A descrição morfológica foi realizada com materiais frescos no Laboratório de Morfologia Vegetal, localizado no Campus Universitário de Alta Floresta, Universidade do Estado de Mato Grosso, com o uso de um estereomicroscópio. Costus spiralis foi caracterizada como ervas com bainha entre 11$15 \mathrm{~cm}$ compr., fechada, lâmina foliar 18-27 × 8,2-11 cm, elíptica a levemente obovada, faces adaxial e abaxial glabras; inflorescência espiciforme, $10-25 \mathrm{~cm}$ compr., terminal, brácteas 4-4,3 × 3,5-4 cm, vermelhas; pétalas avermelhadas; 1 estame petaloide, 5,55,6 cm compr., avermelhado, 2 anteras férteis, 8-9 mm compr., 5 estaminódios conatos em um labelo tubular, 5,8-6,6 $\times 4 \mathrm{~cm}$. Distingue-se facilmente das outras espécies pela bráctea e labelo vermelho a avermelhado. É conhecida em Alta Floresta como cana-debrejo, caninha-do-brejo e cana-de-macaco, além de cana-do-brejo, caninha, caninhade-macaco e pobre-velho em outros municípios. Entre os usos medicinais verificados em Alta Floresta e demais municípios, predomina o chá da folha para problemas renais. O trabalho mostra a importância da morfologia para a identificação da espécie, que é amplamente aceita como recurso medicinal nos ambientes de ocorrência no Brasil.

PALAVRAS-CHAVE: Amazônia; Descrição morfológica; Problemas renais.

\section{MORPHOLOGY OF Costus spiralis (JACQ.) ROSCOE (COSTACEAE): A MEDICINAL SPECIES IN ALTA FLORESTA, MATO GROSSO}

\begin{abstract}
The objective of the research was to present the morphology of organs vegetative and reproductive of Costus spiralis (Jacq.) Roscoe in the municipality of Alta Floresta, Mato Grosso, as well photographs to help identify the species, phytogeographic information and its use in folk medicine. It was carried out between April 2020 and August 2021, through botanical collection in the São Bento community, a rural area in the municipality of Alta Floresta (MT). The morphological description was made with fresh materials in
\end{abstract}


Plant Morphology Laboratory, located in the University Campus of Alta Floresta, Universidade do Estado de Mato Grosso, with the use of a stereomicroscope. Costus spiralis was characterized as herb with a sheath between 11-15 cm long, closed, leaf lamina 18-27 $\times 8.2-11 \mathrm{~cm}$, elliptical to slightly obovate, faces adaxial and abaxial glabrous; spiciform inflorescence, $10-25 \mathrm{~cm}$ long, terminal, bracts $4-4.3 \times 3.5-4 \mathrm{~cm}$, red; reddish petals; 1 petaloid stamen, $5.5-5.6 \mathrm{~cm}$ long, reddish, 2 fertile anthers, 8-9 $\mathrm{mm}$ long, 5 connate staminodes in a tubular labellum, 5.8-6.6 $\times 4 \mathrm{~cm}$. Distinguishes it easily from other species by the bract and lip red to reddish. It is known in Alta Floresta as cana-de-brejo, caninha-do-brejo and cana-de-macaco, In addition to cana-do-brejo, caninha, caninha-de-macaco and pobre-velho in other municipalities. Among the medicinal uses verified in Alta Floresta and other municipalities, the leaf tea predominates for kidney problems. The work shows the importance of morphology for the identification of the species, which is widely accepted as a medicinal resource in environments that occur in Brazil.

KEYWORDS: Amazon; Morphological description; Kidney problems.

\section{INTRODUÇÃO}

A família Costaceae Nakai (Zingiberales) possui distribuição pantropical e está representada pelos gêneros Cheilocostus C. Specht, Chamaecostus C. Specht \& D. W. Stevenson, Costus L., Dimerocostus O. Kuntze, Monocostus K. Schumann, Paracostus C. Specht e Tapeinochilos Miquel (STEVENS, 2021; WFO, 2021), totalizando 125 espécies distribuídas pelo mundo, com centros de diversidade na região neotropical, com 72 espécies, no continente africano, com 30 espécies, e na região sudeste da Ásia, com 23 espécies (VALDERRAMA et al., 2020).

A maioria das espécies ocorre em ambientes expostos a climas quentes e úmidos, como bordas de florestas, estradas e corpos d'água (SALINAS, 2007). As espécies são polinizadas por abelhas ou por beija-flores, porém as inflorescências são constantemente visitadas por formigas atraídas pelo néctar produzido pelos nectários nas brácteas e nas flores (RIBEIRO et al., 1999; STEVENS, 2021).

As espécies são facilmente reconhecidas pelas folhas liguladas com uma bainha fechada, dispostas em uma única espiral no caule, inflorescências geralmente densas, espicato-capitadas e com brácteas grandes, flores com um grande labelo com estaminódios conatos, um único estame e estilete que se estende entre as duas tecas da antera (STEVENS, 2021). A família é relacionada com Zingiberaceae, mas a distinção é facilmente feita com base no tipo de filotaxia; Costaceae possui folhas alternas espiraladas ao passo que Zingiberaceae possui folhas alternas dísticas (SOUZA; LORENZI, 2019).

Costaceae é caracterizada como ervas rizomatosas com crescimento simpodial, perenes; folhas alternas espiraladas, uninérveas ou peniparalelinérveas; bainha fechada; inflorescência cimosa, espiciforme ou raramente reduzidas a uma única flor; flores vistosas, bissexuadas, zigomorfas, diclamídeas e heteroclamídeas; cálice trímero, gamossépalo, prefloração imbricada; estame 1, antera com ambas as tecas férteis, envolvendo o estilete; estaminódios 5, petaloides, unidos entre si, geralmente mais vistosos do que o perianto; anteras rimosas; nectários 2, no topo do ovário; gineceu gamocarpelar, ovário ínfero, tricarpelar ou raramente bicarpelar, trilocular ou raramente bilocular, placentação axial, lóculos pluriovulados; frutos do tipo cápsula; sementes com arilo (SOUZA; LORENZI, 2019). 
No Brasil, a família está representada pelos gêneros Chamaecostus, Costus e Dimerocostus, totalizando 23 espécies, nos domínios fitogeográficos da Amazônia, Caatinga, Cerrado, Mata Atlântica e Pantanal, nos mais diversos tipos de vegetação: Campinarana, Floresta Ciliar, Floresta de Galeria, Floresta de Igapó, Floresta de Terra Firme, Floresta de Várzea, Floresta Estacional Decidual, Floresta Estacional Perenifólia, Floresta Estacional Semidecidual, Floresta Ombrófila, Palmeiral, Restinga, Savana Amazônica e em Vegetação Aquática (ANDRÉ, 2020).

Algumas espécies da família são utilizadas como ornamentais e medicinais. Segundo Souza e Lorenzi (2019) e MBG (2021) o gengibre-abacaxi (Tapeinochilos ananassae (Hassk.) K.Schum.), espécie exótica no Brasil (nativa na Austrália, Nova Guiné e Indonésia), é usada como ornamental devido as inflorescências que surgem diretamente dos rizomas, além de espécies conhecidas como cóstus ou cana-do-brejo, pertencentes ao gênero Costus, algumas destas nativas, no entanto o potencial ornamental das espécies brasileiras é pouco explorado. Castro et al. (2011), apresentaram 12 espécies nativas e exóticas de Costaceae com potencial ornamental no Brasil, baseado no banco de germoplasma de Zingiberales ornamentais do Instituto Agronômico de Campinas (IAC), pertencentes aos gêneros Costus, Cheilocostus e Dimerocostus, com espécies adequadas para paisagismo, cultivo em vasos, cultivo em grandes recipientes, produção de flores de corte e comercialização das hastes foliares, principalmente do gênero Costus, com nove espécies.

O gênero Costus está representado na região neotropical por 57 espécies, considerado o principal gênero da família (VALDERRAMA et al., 2020). No Brasil, possui 15 espécies, quase todas na Amazônia, com 14 espécies, os outros domínios fitogeográficos estão entre duas ou três espécies, exceto o Pampa que até o momento não tem nenhum registro de ocorrência; o estado de Mato Grosso está representado por seis espécies do gênero (ANDRÉ, 2020).

Costus é caracterizado como ervas terrestres rizomatosas, perenes; raízes não tuberosas; caule subterrâneo rizomatoso delgado a robusto; caule aéreo alongado, curvo-espiralado, raramente ramificado; folhas alterno-espiraladas, monoísticas, simples; bainha glabra ou pubescente; lígula curta, comumente inteira, truncada e glabra; pecíolo curto; lâminas elípticas a obovadas; inflorescências terminais com brácteas imbricadas, formando uma espiga, podendo ocorrer em ramo a parte sem folhas; brácteas coriáceas, ovadas, verdes, amarelas ou vermelhas; bractéolas anguladas, dobradas; cálice gamossépalo, persistente no fruto; corola branca, amarela, laranja ou vermelha, elíptica a obovada, pilosa ou glabra; cinco estaminódios fundidos em um longo labelo, ovado no ápice ou tubular, comumente com guias de néctar, labelo branco, amarelo, laranja, vermelho ou rosa, margem inteira; um estame fértil petalóide, elíptico a obovado, branco, amarelo ou laranja; ovário trilocular, glabro ou piloso; estigma bilamelado, estilete encaixado entre as tecas da antera; fruto cápsula loculicida, elipsóide a globosa; sementes pretas ou marrons, com arilo grande e lacerado, branco, comumente unidos no mesmo lóculo quando da deiscência do fruto (ANDRÉ, 2020).

A questão evolutiva e taxonômica do gênero Costus vem sendo abordada recentemente na busca de respostas mais concretas e precisas referentes ao número de espécies e sua origem evolutiva, com pesquisas em várias áreas do conhecimento, como mostrado no estudo citotaxonômico de quatro espécies do gênero ( $C$. spiralis (Jacq.) Roscoe, C. arabicus L., C. scaber Ruiz \& Pav. e C. amazonicus (Loes.) J.F.Macbr.), que encontraram o mesmo número cromossômico $(2 n=18)$ para as 
espécies, mas com heterogeneidade na morfologia cromossômica, evidenciando que os táxons estão em processo evolutivo (FERNANDES et al., 2020).

Rocha et al. (2021) fizeram uma ampla revisão de literatura sobre a importância medicinal das espécies do gênero Costus e verificaram que Costus afer Ker Gawl., $C$. arabicus L., C. pictus D.Don., C. spicatus (Jacq.) Sw. e C. spiralis (Jacq.) Roscoe demonstraram atividades promissoras para o tratamento da inflamação, dor, diabetes e nefrolitíase, tendo relação com algumas alegações de uso popular, porém ainda são necessários outros ensaios que avaliem a segurança dos compostos presentes nas espécies em futuros ensaios clínicos. Costus spiralis é a espécie que mais se destaca em trabalhos de plantas medicinais no Brasil (FERNANDES, 2002; OTONI, 2018; BARBOSA et al., 2019; BORGHEZAN et al., 2021; PEREIRA et al., 2021).

O trabalho teve como objetivo realizar o estudo morfológico de Costus spiralis (Costaceae), uma espécie de importância medicinal no município de Alta Floresta (MT), oferecendo ainda fotografias para facilitar a identificação, comentários taxonômicos, fitogeográficos e medicinais.

\section{MATERIAL E MÉTODOS}

O estudo foi realizado entre abril de 2020 e agosto de 2021, mediante coleta botânica na comunidade rural São Bento (Figura 1), município de Alta Floresta, Mato Grosso. O município está localizado a $830 \mathrm{~km}$ da capital do estado, Cuiabá (PMAF, 2021).

FIGURA 1. Localização da comunidade São Bento no município de Alta Floresta, Mato Grosso.

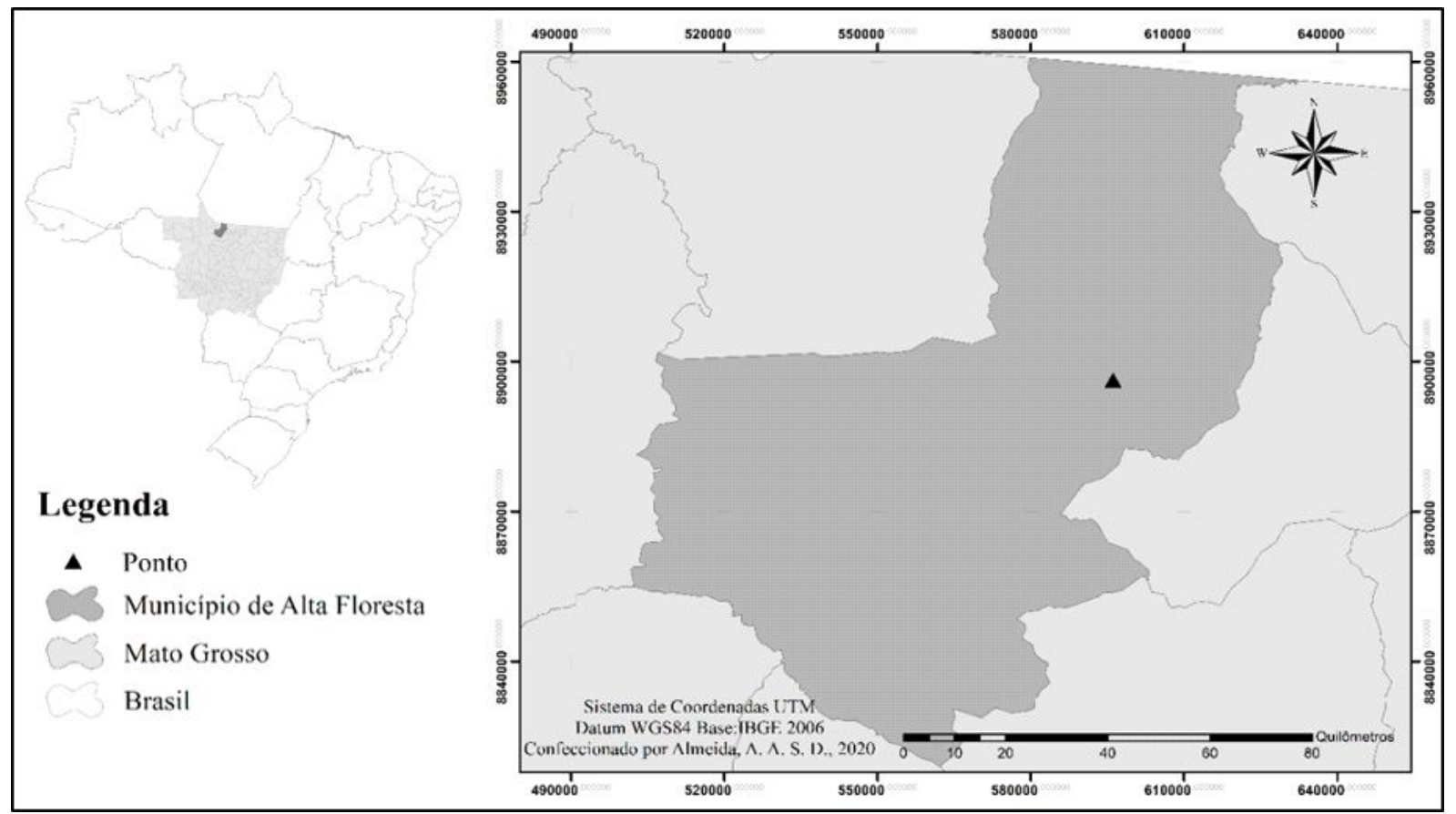

Fonte: Autor (2021) 
As coletas foram realizadas com a retirada de ramos férteis, acondicionados em saco plástico, com os dados de localização, nome científico, data de coleta e características vegetativas e reprodutivas anotados no caderno de campo, conforme as instruções de Fidalgo e Bononi (1989). Os materiais foram levados ao Herbário da Amazônia Meridional (HERBAM), localizado no Campus Universitário de Alta Floresta, da Universidade do Estado de Mato Grosso, posteriormente herborizados conforme metodologias usuais.

A descrição morfológica foi realizada no Laboratório de Morfologia Vegetal localizado no HERBAM, com o uso de amostras frescas e desidratadas da espécie, utilizando-se um estereomicroscópio, papel milimetrado, régua, seringas com agulhas e lâmina de aço. O trabalho fez uso das terminologias de Barroso et al. (1999), Maas (1972) e Radford et al. (1974) para descrição morfológica. O mapa foi elaborado com o uso do software ArcGIS ${ }^{\circledR}$ 10.2.2, licença teste, com as funções do ArcMap e bases cartográficas do Sistema Geodésico Mundial 1984 (WGS-84) e do sistema de projeção Universal Transversa de Mercator (UTM).

\section{RESULTADOS E DISCUSSÃO}

Costus spiralis (Jacq.) Roscoe, Trans. Linn. Soc. London 8: 350. 1807.

Figura $2 \mathrm{~A}-\mathrm{E}$

Ervas 1-2,5 metros de altura, rizomatosas; caule aéreo cilíndrico, glabro, não ramificado. Folhas alternas espiraladas, simples, bainha 11-15 centímetros de comprimento, fechada, glabra, lígula 6-10 milímetros de comprimento, truncada, lâmina 18-27 × 8,2-11 centímetros, elíptica a levemente obovada, base cordada, ápice acuminado, faces adaxial e abaxial glabras, margem inteira, cartácea. Inflorescência cimosa, espiciforme, 10-25 cm compr., terminal, brácteas 4-4,3 × 3,5-4 cm, vermelhas, 1 bractéola por flor, 2,3-2,6 × 0,9-1 cm, vermelha. Flores subsésseis, vistosas, trímeras, zigomorfas, cálice tubular, sépalas 9-11 mm compr., pubescentes, vermelhas; corola gamopétala, 2 pétalas inferiores, 5,5-5,6 × 1,5-1,6 cm, avermelhadas, glabras, 1 pétala superior, 5,5-5,6 × 2,4-2,5 cm, avermelhada, ápice amarelado, glabra; 1 estame petaloide, 5,5-5,6 cm compr., avermelhado, antera 8-9 mm compr., rimosa, 2 tecas férteis, 5 estaminódios conatos formando 1 labelo tubular, 5,8-6,6 $\times 4 \mathrm{~cm}$ compr., base branco-amarelados, 2 estaminódios laterais com ápice branco-avermelhados e 3 centrais com ápice amarelo-avermelhados; gineceu tricarpelar, ovário ínfero, $0,8-1 \mathrm{~cm}$ compr., trilocular, pluriovulado, placentação axial, velutino, estilete $3,8-4 \mathrm{~cm}$ compr., estigma flabelado, com apêndice lateral bilobado. Fruto tipo cápsula $8-1,2 \times 0,8-0,9$ $\mathrm{mm}$, velutino; semente 3,7-4 × 2,2-3 mm, obovada, enegrecida, arilo abundante, lacerado. Material testemunho: J. M. Fernandes 1632 (HERBAM), J. M. Fernandes 1800 (HERBAM).

Costus spiralis (Jacq.) Roscoe pode ser facilmente reconhecida no campo por sua inflorescência vermelha e flores rosa-avermelhadas a vermelho-salmão, e assemelha muito as espécies Costus spicatus e Costus scaber (MAAS, 1972), conforme apresentado no quadro 1 e na figura 3. A espécie $C$. spiralis possui duas variedades no Brasil, Costus spiralis (Jacquin) Roscoe var. spiralis, reconhecida pelas folhas glabras, e Costus spiralis var. villosus Maas, pelas folhas com indumento viloso (MAAS, 1972; ANDRÉ, 2020). Os materiais examinados em Alta Floresta, pertencem a C. spiralis var. spiralis, devido a presença de folhas glabras. 
QUADRO 1. Características morfológicas de três espécies relacionadas de Costus.

\begin{tabular}{|l|l|l|l|}
\hline Características & Costus spicatus & Costus spiralis & Costus scaber \\
\hline $\begin{array}{l}\text { Face superior da } \\
\text { folha }^{1}\end{array}$ & estrigulosa a glabra & glabra & $\begin{array}{l}\text { estrigulosa, raramente } \\
\text { glabra }\end{array}$ \\
\hline Cor da bráctea $^{1}$ & $\begin{array}{l}\text { parte coberta } \\
\text { avermelhada, parte } \\
\text { exposta esverdeada } \\
\text { a avermelhada }\end{array}$ & vermelho escuro & laranja-avermelhado \\
\hline Bractéola $^{1}$ & $17-30 \mathrm{~mm}$ & $15-29 \mathrm{~mm}$ & $9-12(-17) \mathrm{mm}$ \\
\hline Cálice $^{1}$ & $9-16 \mathrm{~mm}$ & $7-12(-15) \mathrm{mm}$ & $3-7 \mathrm{~mm}$ \\
\hline Corola $^{1}$ & $\begin{array}{l}40-50 \mathrm{~mm} \text {, amarela } \\
\text { a rosa }\end{array}$ & $\begin{array}{l}45-60 \mathrm{~mm}, \\
\text { vermelha rosada }\end{array}$ & $\begin{array}{l}35-40 \mathrm{~mm} \text { laranja a } \\
\text { amarela }\end{array}$ \\
\hline Labelo $^{1}$ & $25-30 \mathrm{~mm}$, amarelo & $\begin{array}{l}25-30 \mathrm{~mm}, \\
\text { vermelho-rosado }\end{array}$ & $20-30 \mathrm{~mm}$, amarelo \\
\hline Estame $^{1}$ & $30-40 \times 10 \mathrm{~mm}$ & $25-30 \times 5-10 \mathrm{~mm}$ & $20-25 \times 6-8 \mathrm{~mm}$ \\
\hline Ápice do estame $^{1}$ & $\begin{array}{l}\text { obtuso ou } \\
\text { arredondado }\end{array}$ & $\begin{array}{l}\text { emarginado, } \\
\text { raramente inteiro }\end{array}$ & obtuso \\
\hline Antera $^{1}$ & $7-8 \mathrm{~mm}$ & $7-9 \mathrm{~mm}$ & $5-7 \mathrm{~mm}$ \\
\hline Origem no Brasi $^{2}$ & exótica & nativa & nativa \\
\hline
\end{tabular}

Fonte: ${ }^{1}$ Maas (1972); ${ }^{2}$ André (2020).

A espécie está distribuída nas regiões tropicais da América do Sul, exceto na parte ocidental, entre 350 metros a 1800 metros de altitude em relação ao nível do mar (MAAS, 1972; MAAS-KAMER; MAAS, 2003). No Brasil, ocorre em todas as regiões, estados e no Distrito Federal (ANDRÉ, 2020).

Em Alta Floresta (MT) é conhecida como cana-de-brejo e facilmente encontrada em locais úmidos como floresta de galeria, floresta ciliar e floresta de várzea, além de cultivada em quintais urbanos e rurais para fins medicinais e ornamentais. De acordo com o conhecimento popular no município, a infusão das folhas e rizomas é utilizada para problemas renais e ação diurética, além de leucorreia, febre e catarro vesicular (FERNANDES, 2002). Ainda em Alta Floresta, Silva et al. (2019) relataram que a espécie é conhecida por moradores dos bairros "Cidade Alta" e "Setor F" como caninhado-brejo, com o chá utilizado para o tratamento dos rins e pedra nos rins; Pereira et al. (2021) citam que é conhecida como cana-de-macaco e usada como medicinal entre moradores de nove comunidades rurais em Alta Floresta e em 10 comunidades rurais em Nova Canaã do Norte (MT).

Como Costus spiralis é uma espécie nativa e com ampla distribuição no Brasil, vem sendo utilizada como um recurso medicinal em diferentes localidades do país. Em quintais urbanos no município de Manaus (AM) é conhecida como pobre-velho, com o chá das folhas usado para problemas renais (BARBOSA et al., 2019). Borghezan et al. (2021) citam que a espécie é medicinal entre moradores de quintais urbanos no município de Orleans (SC), conhecida como cana-do-brejo; Otoni (2018) cita que é conhecida entre moradores de comunidades quilombolas e indígenas no município de Araçuaí (MG) como caninha, caninha-do-brejo e caninha-de-macaco, fazendo uso do chá das folhas para problemas renais; Sauini et al. (2020) citam que é conhecida como caninha-do-brejo entre quilombolas no município de Ubatuba (SP), utilizada para o tratamento dos rins; e, Silva et al. (2015) apresentam a espécie como cana-do-brejo 
entre agricultores familiares de Solânea (PB), que fazem o uso do chá das folhas para rins e pressão alta.

FIGURA 2. Morfologia de Costus spiralis: $A$, hábito; $B$, parte da haste com bainha $\left({ }^{*}\right)$ e lígula $\left({ }^{* *}\right)$; C, parte da inflorescência com uma flor; D, bractéola (seta 1), cálice (seta 2), pétala (seta 3), labelo (seta 4); $E$, estame (seta 1), antera (seta 2), ovário (seta 3), estilete (seta 4); F, fruto com cálice persistente vermelho (1), semente (seta 2); G, semente (seta 1), arilo (seta 2).
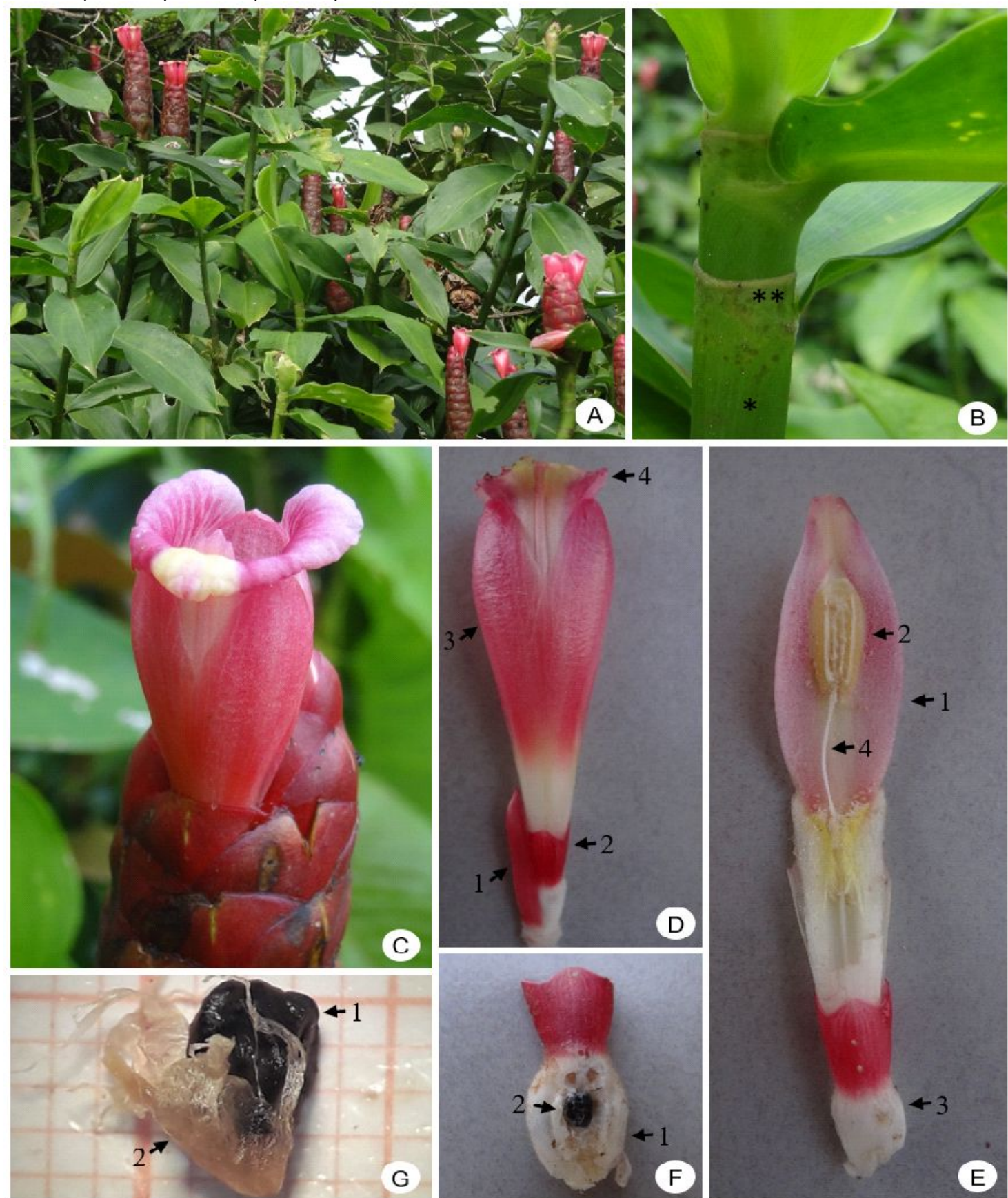

Fonte: Autor (2021) 
FIGURA 3. Espécies de Costus relacionadas a Costus spiralis: A, Costus scaber ramo com folhas, inflorescência e flor; B, Costus spicatus - ramo com folhas, inflorescência e flor.
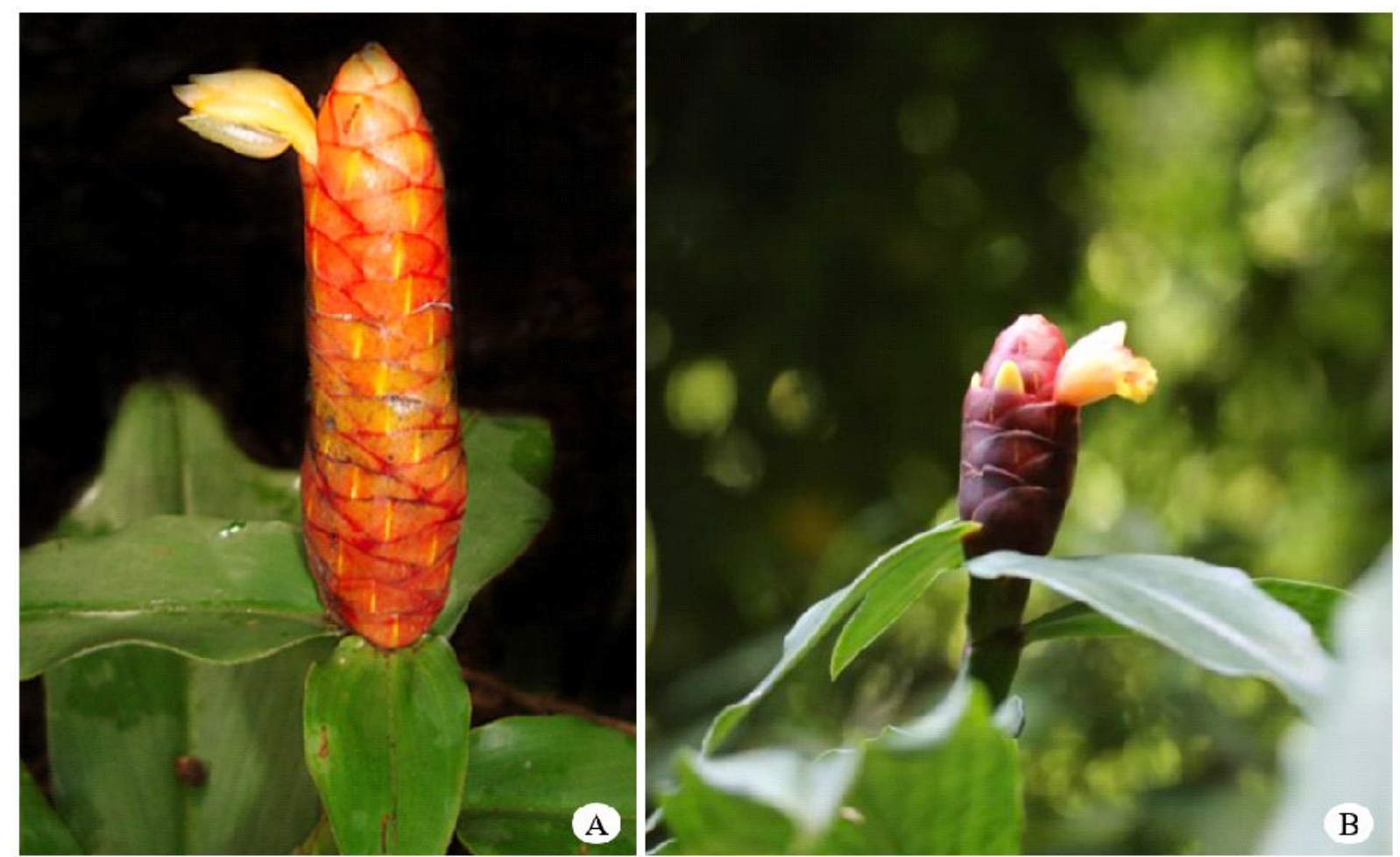

Fonte: F. Figueiredo (A); Aitor (B).

A espécie Costus spiralis demonstra possíveis atividades biológicas devido à presença de metabólitos secundários que contribuem para terapia de várias doenças, são eles: fenóis, alcaloides, flavonoides e taninos, que contribuem para sua ação antiurolítica, anti-inflamatória, diurética, adstringente e hipoglicemia, comprovando-se essas propriedades por meio de bases empíricas (SANTOS et al., 2020).

\section{CONCLUSÃO}

A cana-do-brejo (Costus spiralis) é facilmente reconhecida por características de inflorescência e flor, distinguindo-se facilmente de espécies próximas (Costus spicatus e Costus scaber); entre os usos medicinais verificados na região de Alta Floresta (MT), predomina o chá da folha para problemas renais.

O trabalho mostra a importância da morfologia para a identificação da espécie, que é amplamente aceita como recurso medicinal nos ambientes de ocorrência no Brasil.

\section{REFERÊNCIAS}

ANDRÉ, T. Costaceae in Flora do Brasil 2020. 2020. Jardim Botânico do Rio de Janeiro. Disponível em: <http://floradobrasil.jbrj.gov.br/reflora/floradobrasil/FB110631>. Acesso em: 23/06/2021.

BARBOSA, C. S.; SCUDELLER, V. V.; FERREIRA, S. A. N.; BONATTO, E. C. S.; 
PINTO, E. O. S. Plantas medicinais cultivadas em quintais no bairro de São Raimundo, da cidade de Manaus, AM. Revista Terceira Margem Amazônia, v. 4, n. 12, p. 122 141, 2019. DOI: https://doi.org/10.36882/2525-4812.2019v4i12p\%25p

BARROSO, G. M.; MORIM, M. P.; PEIXOTO, A. L.; ICHASSO, C. L. F. Frutos e sementes: morfologia aplicada a sistemática de dicotiledôneas. Viçosa: Imprensa Universitária, 1999.

BORGHEZAN, J. M.; ROSSATO, A. E.; CITADINI-ZANETTE, V. Plantas Medicinais nos quintais urbanos do município de Orleans, Santa Catarina, Sul do Brasil. Ensaios e Ciência, v. 25, n. 2, p. 224-231, 2021. DOI: https://doi.org/10.17921/14156938.2021v25n2p224-231

CASTRO, C. E. F.; MOREIRA, S. R.; CASTRO, A. C. R.; SOUZA, F. V. D.; LOGES, V.; et al. Avaliação de espécies de Costaceae para uso ornamental. Revista Brasileira de Horticultura Ornamental, v. 17, n. 1, p. 63-74, 2011. DOI: https://doi.org/10.14295/rbho.v17i1.719

FERNANDES, J. M. Plantas medicinais de Alta Floresta: com contribuição à etnobotânica. Alta Floresta: Gráfica Cidade, 2002.

FERNANDES, L.; KARSBURG, I. V.; MELLO, V. S.; GALLO, R. Cariótipo e conteúdo de DNA nuclear de quatro espécies do gênero Costus L.: uma contribuição citotaxonômica e evolutiva. Brazilian Journal of Development, v. 6, n. 9, p. 72196-72217, 2020. DOI:10.34117/bjdv6n9-606

FIDALGO, O.; BONONI, V. L. R. Técnicas de coleta, preservação e herborização do material botânico. São Paulo: Instituto de Botânica de São Paulo, 1989.

MAAS, P. J. M. Costoideae (Zingiberaceae) - Flora Neotropica. Vol. 8. New York: New York Botanical Garden, 1972.

MAAS-KAMER, H.; MAAS, P. J. M. Costaceae. In: WANDERLEY, M. G. L.; SHEPERD, G. J.; GIULETTI, A. M.; MELHEM, T. S.; KIRIZAWA, M. (eds). Flora Fanerogâmica do Estado de São Paulo, v. 3. São Paulo: FAPESP \& Hucitec, p. 63-65, 2003.

MBG - Missouri Botanical Garden. Tapeinochilos ananassae. Disponível em: http://www.missouribotanicalgarden.org/PlantFinder/PlantFinderDetails.aspx?taxonid=29 2693. Acesso em: 30/07/2021.

OTONI, T. C. O. Levantamento etnobotânico de plantas utilizadas com fins medicinais e cosméticos em comunidades tradicionais do município de Araçuaí, Minas Gerais. 2018. 195 p. Dissertação (Mestrado em Ciências Farmacêuticas) Universidade Federal dos Vales do Jequitinhonha e Mucuri, Diamantina

PEREIRA, A. G.; AlCANTARA, L. C. S.; OliVEIRA, R. E.; SAIS, A. C. Plantas com potencial medicinal em quintais agroflorestais: diversidade entre comunidades rurais do 
Portal da Amazônia - Mato Grosso, Brasil. Research, Society and Development, v. 10, n. 6, e59010615713, 2021. DOI: http://dx.doi.org/10.33448/rsd-v10i6.15713

PMAF - Prefeitura Municipal de Alta Floresta. Geografia. 2021. Disponível em https://www.gp.srv.br/transparencia_altafloresta/servlet/inf_div_detalhe?12>. Acesso em: 19/07/2021.

RADFORD, A. E.; DICKISON, W. C.; MASSEY, J. R.; BELL, C. R. Vascular plant systematics. New York: Harper \& Row, 1974.

RIBEIRO, J. E. L. S., HOPKINS, M. J. G., VICENTINI, A., SOTHERS, C. A., COSTA, M. A. $S$.; et al. Flora da Reserva Ducke: guia de identificação das plantas vasculares de uma floresta de terra firme na Amazônia Central. Manaus: INPA-DFID, 1999.

ROCHA, N. S. C.; CHAGAS, C. K. S.; NUNES, L. S.; BARROS, R. C.; TOMAZ, J. M. O.; DOLABELA, M. F.; et al. Costus spp e sua relevância medicinal: uma revisão integrativa. Research, Society and Development, v. 10, n. 8, e4410816902, 2021. DOI: http://dx.doi.org/10.33448/rsd-v10i8.16902

SALINAS, N. R. Una nueva especie de Costus (Costaceae) de la Amazonia colombiana. $\begin{array}{lllllll}\text { Caldasia, } & \text { v. } 29, \quad \text { n. } & 2, & \text { p. } & 195-201, & \text { URL: }\end{array}$ http://www.scielo.org.co/pdf/cal/v29n2/v29n2a1.pdf

SANTOS, R. C.; LIMA, V. S.; NUNES, J. V. N.; FEITOSA, J. M.; RAMOS, R. M.; et al. Aspectos biológicos do gênero Costus com enfâse na Costus Spiralis. Brazilian Journal of Development, v. 6, n. 10, p. 78703-78716, 2020. DOI: 10.34117/bjdv6n10341

SAUINI, T.; FONSECA-KRUEL, V. S.; YAZBEK, P. B.; MATTA, P.; CASSAS, F.; et al. Participatory methods on the recording of traditional knowledge about medicinal plants in Atlantic Forest, Ubatuba, São Paulo, Brazil. Plos One, v. 15, p. e0232288, 2020. DOI: https://doi.org/10.1371/journal.pone.0232288

SILVA, J. R. O.; SILVA, I. C. O.; COELHO, M. F. B.; CAMILI, E. C. As plantas e seus usos nos quintais de Alta Floresta, Mato Grosso. Revista Verde, v. 14, n. 3, p. 420-428, 2019. DOI: https://doi.org/10.18378/rvads.v14i3.6086

SILVA, M. D. P.; MARINI, F. S.; MELO, R. S. Levantamento de plantas medicinais cultivadas no município de Solânea, agreste paraibano: reconhecimento e valorização do saber tradicional. Revista Brasileira de Plantas Medicinais, v. 17, n. 4, supl. II, p. 881-890, 2015. DOI: https://doi.org/10.1590/1983-084X/14_112

SOUZA, V. C.; LORENZI, H. Botânica sistemática: guia ilustrado para identificação das famílias de fanerógamas nativas e exóticas no Brasil, baseado no APG IV. 4 ed. Nova Odessa: Instituto Plantarum de Estudos da Flora, 2019.

STEVENS, P. F. Angiosperm Phylogeny Website. Version 14, July 2017 [and more or 
less continuously updated since] - page last updated 21/05/2021. Disponível em: http://www.mobot.org/MOBOT/research/APweb/. Acesso em: 30/07/2021.

VALDERRAMA, E.; SASS, C.; PINILLA-VARGAS, M.; SKINNER, D.; MAAS, P. J. M.; et al. Unraveling the spiraling radiation: a phylogenomic analysis of neotropical Costus $\mathrm{L}$. Frontiers in Plant Science, v. 11, p. 1-16, 2020. DOI: https://doi.org/10.3389/fpls.2020.01195

WFO - World Flora Online. An online flora of all known plants: supporting the global strategy for plant conservation. Disponível em: http://www.worldfloraonline.org. Acesso em: 30/07/2021. 